\title{
AN ADAPTIVE NEUROCONTROLLER FOR INDUCTION MOTORS
}

The paper is focused on presenting possibilities of applying artificial neural networks (ANN) at creating a speed controller of an induction motor drive. The presented method of control takes advantage of approximating properties of multi-layer feedforward networks. The availability of the proposed neurocontroller is verified through the Matlab simulation. The effectiveness of the controller is demonstrated for different operating conditions and motor parameter changes of the drive system.

Keywords: Neural network, control, induction motor.

\section{Introduction}

Most of the technical systems in practice are non-linear. However, many systems can be represented without any significant loss of accuracy by an equivalent linear representation. Control designs based on system linearization are a widely applied technique in the industry. Other systems are increasingly characterized by complex non-linear dynamics (e.g. high non-linearity, abrupt parameter variations, external disturbances etc.). The important nonlinear diversity is the main reason why no systematic and generally applicable theory for non-linear control design has been developed yet. It is the ability of the artificial neural networks to model nonlinear systems that can be the most readily exploited in the synthesis of non-linear controllers. Neural networks have been used to formulate a variety of control strategies [1] [5].

Two basic design approaches are [2]:

- direct inverse control - it uses a neural inverse model of the system as a controller,

- indirect design - the controller uses a neural network to predict the system output.

Different structures of neurocontrollers for control of non/linear systems, especially induction motor drive have been presented [6] - [13].

We are interested in different already existing methods used to develop a neural controller based on an inverse model of a system. The main idea of the design was to design an adaptive neuro controller of induction motor only on based input-output motor parameters. These parameters were defined as the stator voltages and currents and rotor speed.
Following part of the paper is focused on explaining the method and demonstration the use of ANN for purposes of controlling in simulation studies for a squirrel-cage induction motor drive. Last part of the paper demonstrates sensitivity of the speed controller to motor parameters changes.

\section{Design of the controller}

In real life, the most frequently used are two concepts of inverse neural model architecture: the general training and specialized training architecture [2]. The latter architecture brings some advantages when compared with the former one: The method is intended directly for controlling and in the case of multidimensional systems, as a drive with an induction motor, the model can closely simulate a real system.

Multi-layer neural networks (MLP) can be utilized when creating a system inverse neural model. The use of the MLP type static neural networks presents the simplest solution, however the representation of the system dynamic remains problematic with this neural model. The application of a MLP type neural network with time delaying of the input layer signals can present the solution for introducing the process dynamics into MLP type static neural network. The solution falls among the simplest ones, and the advantage of utilizing this network type rests with the opportunity of its training by traditional backpropagation algorithm for multi-layer networks.

The main requirement we have specified is maintaining the desired speed of the induction motor. Considered for the neurocontroller output were the voltage components that would present

\footnotetext{
* Peter Girovsky ${ }^{1}$, Jaroslava Zilkova ${ }^{1}$, Jaroslav Timko ${ }^{1}$, Jan Girovsky ${ }^{2}$

${ }^{1}$ Department of Electrical Drives and Mechatronics, Technical University of Kosice, Slovakia, E-mail: peter.girovsky@tuke.sk

${ }^{2}$ Laboratory for Micro and Nanotechnology, Paul Scherrer Institut, Villigen, Switzerland
} 
an action intervention for PWM modulation, which would eventually produce the stator voltage desired values from the mains voltage (rectified via using an uncontrolled rectifier). Since the neurocontroller output in such a structure is not directly equal to voltage fed into the motor we have abandoned the idea to establish an accurate inverse model; considered for input quantity of the quasiinverse neural model were rather the desired and at a time also real (measured) motor speeds (Fig. 1).

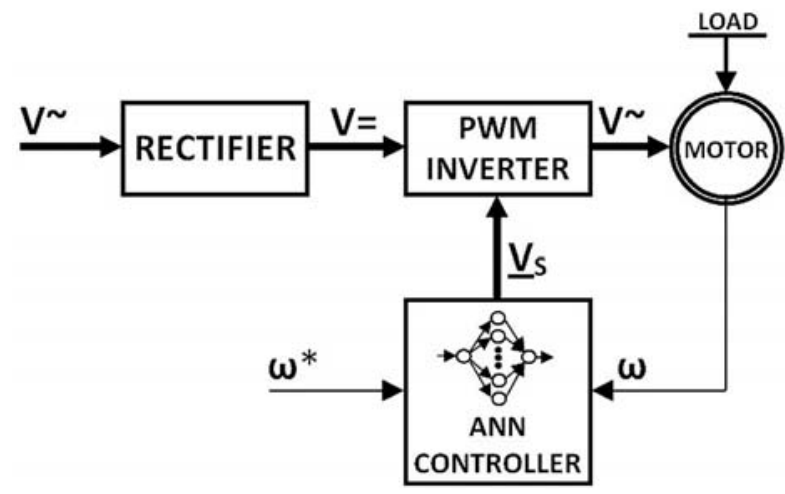

Fig. 1 ANN induction motor control scheme

The design of the neurocontroller is based rightly on known values of these speeds. A typical technique for control synthesis purposes is based on using a description of the induction motor in rotating reference frames $(x, y)$. The use of such rotating reference frames has the benefit of simplifying the model of the motor from the point of view of controller design. In this section design of the neural controller will be presented.

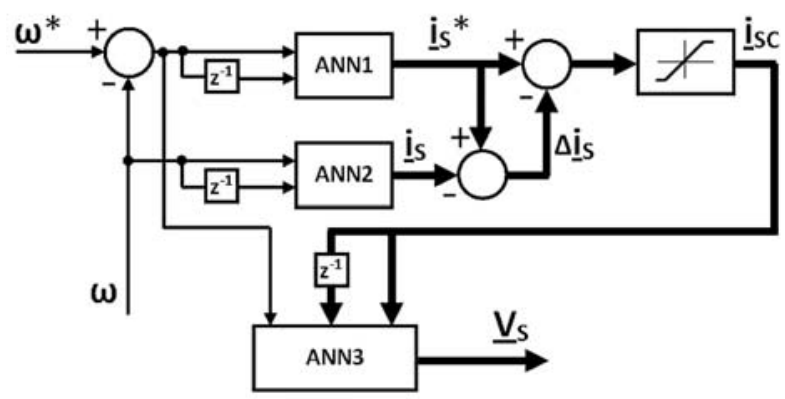

Fig. 2 Block scheme of the ANN controller

The neurocontroller (Fig. 2) consists of three multilayer perceptron (MLP) networks with backpropagation learning algorithm.

The first subsystem ANN1 of the neurocontroller serves for desired current components reconstruction and the second subsystem, ANN2 serves for real current components identification. To reduce the value of the control current in control structure was used saturation block.
The third of them, ANN3 serves for corresponding voltage components reconstruction for PWM converter. These voltage components present action intervention for PWM modulation that would make up the desired stator voltage values from the mains voltage (rectified using an uncontrolled rectifier). The overall control structure is shown in Fig. 1.

The first and second neural networks are identical. Their inputs are values of angular speed, expected and actual, in $k$-th and $(k-1)$ th step. The structure of the ANNs is shown in Fig. 3.

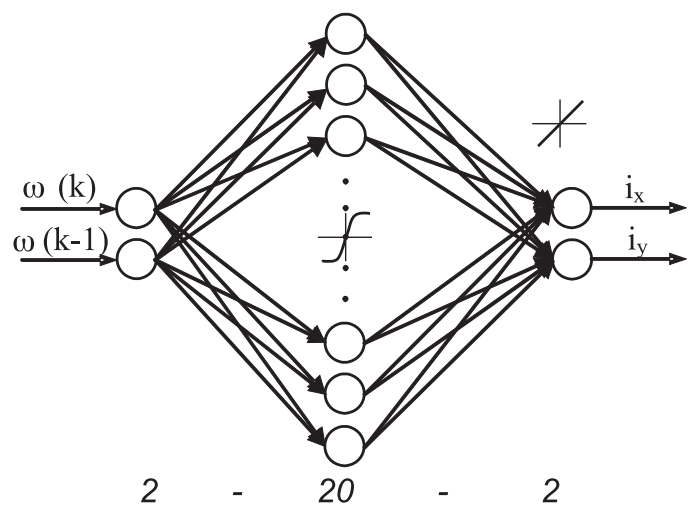

Fig. 3 The structure of the ANN1 and ANN2

The neural networks are trained to approximate the time-varying function of $\mathrm{f}$ and to give the ANN estimated one-step-ahead predicted stator current components:

$$
\begin{aligned}
& i_{s x}^{*}(k+1)=f\left[\omega^{*}(k), \omega^{*}(k-1), w\right], \\
& i_{s y}^{*}(k+1)=f\left[\omega^{*}(k), \omega^{*}(k-1), w\right],
\end{aligned}
$$

and

$$
\begin{aligned}
& i_{s x}(k+1)=f[\omega(k), \omega(k-1), w], \\
& i_{s y}(k+1)=f[\omega(k), \omega(k-1), w] .
\end{aligned}
$$

Reconstructed actual stator current (1) corrects desired value of current from the first ANN (2):

$$
\Delta i_{s}(k+1)=i_{s}^{*}(k+1)-i_{s}(k+1)
$$

Resulting signal of the correction:

$$
i_{s c}(k+1)=i_{s}^{*}(k+1)+\Delta i_{s}(k+1)
$$

in $k$-th and $(k-1)$ th steps and the desired speed value present inputs to the third ANN, which generates appropriate voltage values for PWM converter:

$$
u_{s}(k+1)=g\left[i_{s c}(k+1), i_{s c}(k), \omega^{*}, w\right]
$$


The structure of the ANN3 is shown in Fig. 4.

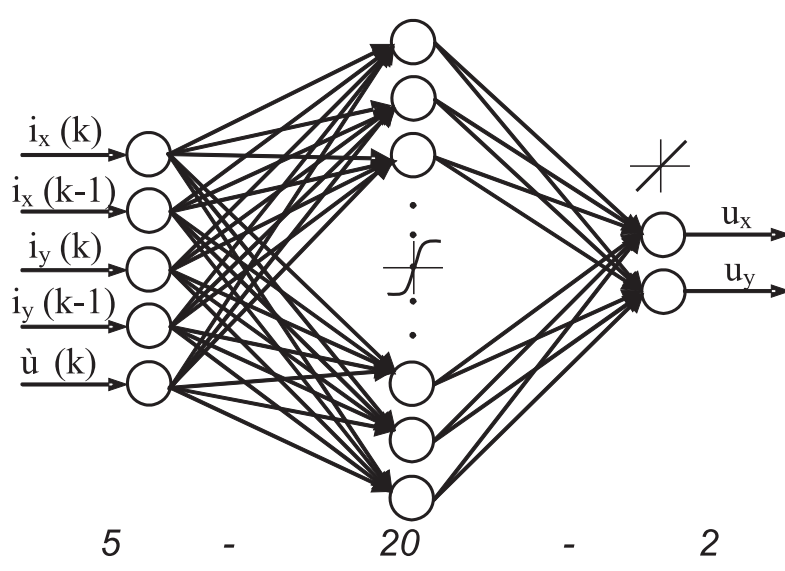

Fig. 4 The structure of the ANN3

MLP networks are used for all $f$ and $g$ approximations. The number of inputs to each of them is determined by the relation (1), (2) or (5). Twenty hidden neurons in one hidden layer of every neural subsystem employ the hyperbolic tangent functions.

All the networks are trained off-line in order to minimise the control performance. Training patterns for an ANN controller were prepared by numerical simulations of the induction motor model with help of Matlab/Simulink and Neural Network Toolbox. In simulations the nominal data of a $3 \mathrm{~kW}$ induction motor were used. The backpropagation training algorithm with Levenberg-Marquardt's modification was used for the training procedures.

\section{Simulation results}

Presented in this section will be the results simulated in MATLAB environment for given connection of the control diagram shown in Fig. 1, where the designed neural controller was implemented. The testing of the neural controller was performed on the induction motor with the following motor parameters:

$$
\begin{aligned}
& U=220 \mathrm{~V} / 50 \mathrm{~Hz}, I_{N}=6.9 \mathrm{~A}, P=3 \mathrm{~kW}, n_{N}=1420 \mathrm{rpm}, \\
& R_{1}=1.81 \Omega, R_{2}=1.91 \Omega, L_{1 \sigma}=L_{2 \sigma}=0.00885 \mathrm{H}, \\
& L_{h}=0.184 \mathrm{H}, p_{p}=2, T_{N}=20.17 \mathrm{Nm}, J_{N}=0.1 \mathrm{kgm}^{2},
\end{aligned}
$$

where:

$U$ - voltage

$I_{N} \quad$ - nominal current

$P_{N} \quad$ - nominal power

$\mathrm{nN}$ - nominal speed

$R_{1}, R_{2}$ - stator and rotor resistance

$L_{1 \sigma}, L_{2 \sigma}, L_{h}$ - stator stray, rotor stray and main inductance

$p_{p} \quad$ - number of pole pairs

\section{$T_{N} \quad$ - nominal torque \\ $J_{N} \quad$ - nominal moment of inertia}

In the following figures the speed control quality is presented. The neural speed controller was trained in the wide range of speed and load torque changes based on the simultation results obtained for induction motor model. Then the trained controller was tested for speed reference signal different than the one used in the training procedures. These test signals together with results of simulations are presented in Figs. 5 and 6. The characteristics were obtained for nominal parameters of the induction motor.

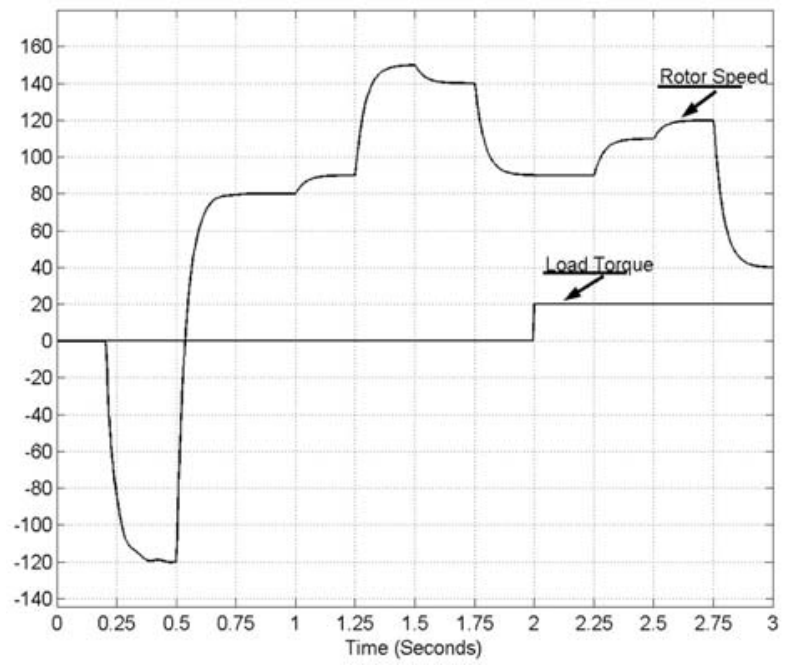

Fig. 5 The course of angular speed at changes speed reference value and at change of load torque

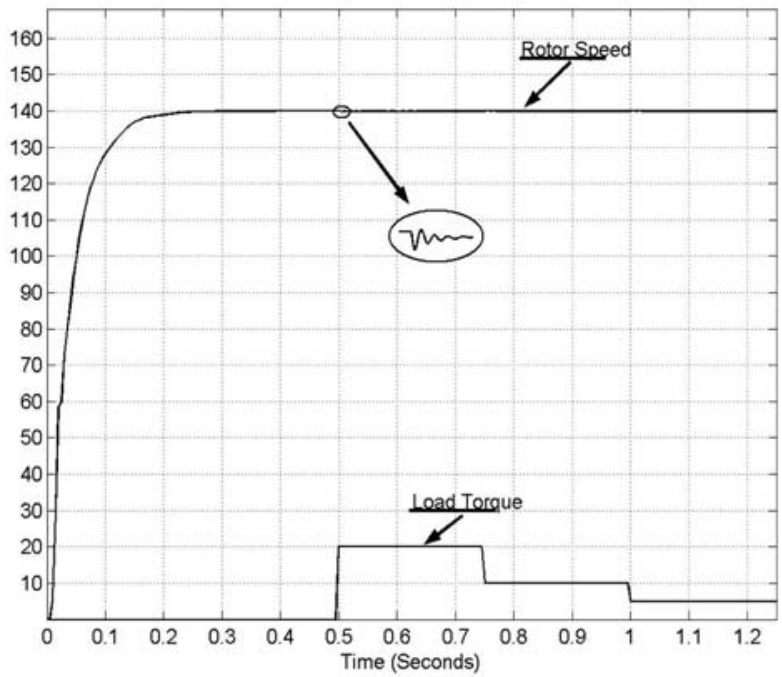

Fig. 6 The course of motor speed at load test 
A. Sensitivity of the speed controller to motor parameter changes The trained controller was tested also for changed motor parameters different than the one used in the training procedures. These test signals together with results of simulations are presented in Figs. 7, 8 and 9 .

Figure 7 illustrates the courses of the motor speed if the moment of inertia $J$ is equal to: $J 1$ for the nominal value, $J 2$ for $200 \%$ and $J 3$ for $300 \%$ of the nominal value of moment of inertia.

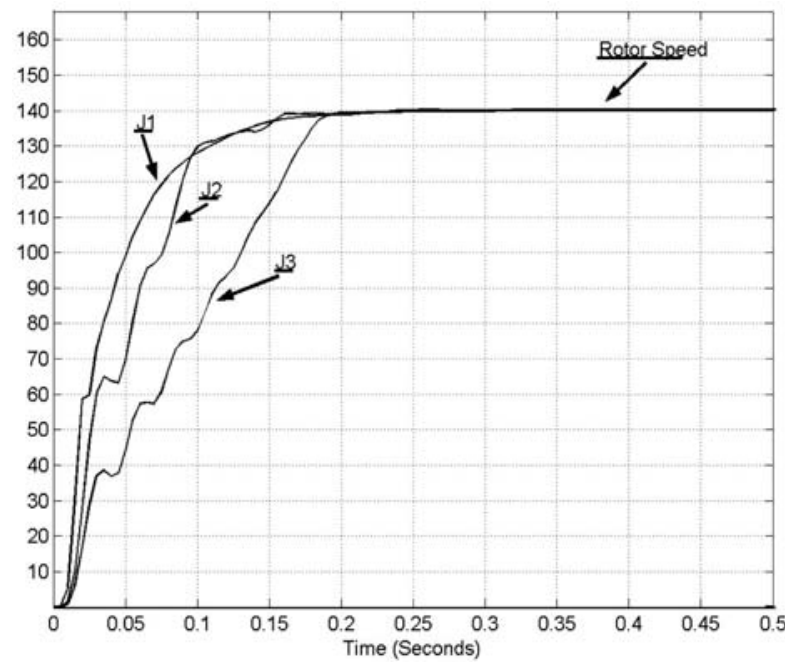

Fig. 7 The courses of the angular motor speed for moment of inertia changes

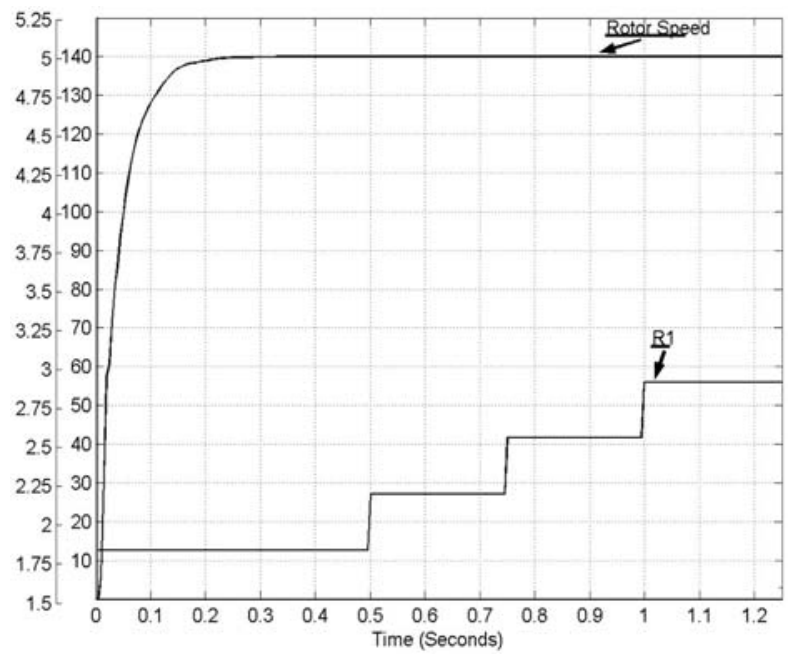

Fig. 8 The course of the motor speed for stator resistance changes

Figure 8 illustrates the courses of the motor speed if the stator resistance $R_{1}$ is gradually changed from nominal value in $t=0,5 \mathrm{~s}$ to the $160 \%$ of nominal value $R_{1}$.

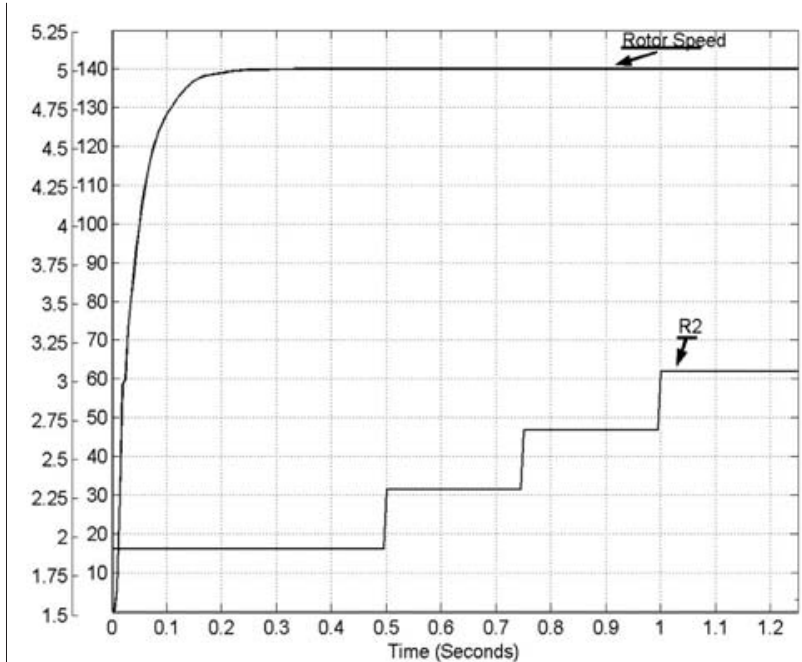

Fig. 9 The course of the motor speed for rotor resistance changes

Figure 9 illustrates the courses of the motor speed if the rotor resistance $R_{2}$ is gradually changed from nominal value in $t=0.5 \mathrm{~s}$ to the $160 \%$ of nominal value $R_{2}$

\section{Conclusion}

The paper deals with the design of a neural controller for induction motor drive control based on a quasi-inverse model of the system. The design of the controller is based on sensor information relating to angular speed of an induction motor. The control task is to reach the motor desired angular speed. The neurocontroller consists of three feedforward neural networks with Levenberg-Marquardt modification of backpropagation learning algorithm. Hidden neurons in each hidden layer of neural subsystems employ the hyperbolic tangent functions. All the networks are trained off-line mode in order to minimise the control performance. Training samples for training of the ANN subsystems were obtained via simulation of an induction motor model in MATLAB environment. First subsystem of the neurocontroller serves for reconstruction of desired current components and the second subsystem serves for reconstruction of real current components. The third of them serves for corresponding voltage components reconstruction for PWM converter. The controller was tested on motor parameters changes, like moment of inertia, stator and rotor resistances.

Obtained simulation results demonstrated good performance of this method.

\section{Acknowledgement}

The authors wish to thank for the support to the R\&D operational program Centre of excellence of power electronics systems and materials for their components No. OPVaV-2008/2.1/01SORO, ITMS 26220120003 funded by European regional development fund (ERDF).

Thanks for the support to project APVV-0185-10. 


\section{References}

[1] LEVIN, A. U., NARENDA, K. S.: Control of Nonlinear Dynamical Systems Using Neural Networks: Controllability and Stabilization. IEEE Transactions on Neural Networks, vol. 4, 1993, pp.192-206.

[2] LEVIN, A. U., NARENDA, K. S.: Control of Nonlinear Dynamical Systems Using Neural Networks - Part II: Observability, Identification and Control. IEEE Transactions on Neural Networks, vol. 7, 1996, pp. 30-42.

[3] VAS, P.: Artificial Intelligence Based Electrical Machines and Drives. Oxford : Oxford University Press, 1999.

[4] ZILKOVA, J.: Artificial Neural Networks in Process Control, Kosice : Mercury-Smekal, 2001, 49 p., ISBN 80-89061-15-X.

[5] BORBEL, M., ZILKOVA, J., TIMKO, J.: Inverse Control of the DC Motor Using Neural Network (in Slovak), Proc. SYMEP, Praha, 2004, p. 5.

[6] BRDYS, M. A., KULAWSKI, G. J.: Dynamic Neural Controllers for Induction Motor, IEEE Transactions on Neural Networks, vol. 10, 1999, No. 2, pp. 340-355.

[7] BURTON, B., HARLEY, R. G., DIANA, G., RODGERSON, J. L.: Implementation of a Neural Network to Adaptively Identify and Control VSI-Fed Induction Motor Stator Currents, IEEE Transaction on Industry Applications, vol. 34, No. 3, 1998.

[8] GIROVSKY, P., TIMKO, J., ZILKOVA, J.: Modeling of Neural Network Speed Estimator for Field Oriented Control of Induction Motor, Metalurgija, vol. 49, No. 2, 2010, pp. 231-235.

[9] KUCHAR, M., BRANDSTETTER, P., KADUCH, M.: Sensorless Induction Motor Drive with Neural Network, IEEE Annu. PowerElec. Specialists Conf., 2004, pp. 3301-3305.

[10] TIMKO, J., ZILKOVA, J., GIROVSKY, P.: Modeling and Control of Electric Drives Using Neural Networks (in Slovak), Kosice : Cpress, 2009. 202 p., ISBN 978-80-8086-124-7.

[11] VITTEK, J., BRIS, P., STULRAJTER, M., PACHA, M.: Chattering Free Sliding Mode Control Law for Position Control of the Drive Employing Induction Motor, Power Engineering Conference 2008, AUPEC '08, Australasian Universities, 2008, pp. 1-6, 14-17.

[12] WISHART, M., HARLEY, T. R. G.: Identification and Control of Induction Machines Using Artificial Neural Networks, IEEE Transaction on Industry Applications, vol. 31, No. 3, 1995.

[13] VITTEK, J., ALTUS, J., BEDNARIK, B., TABACEK, R., DODDS, S. J., PERRYMAN, R.: Research of New Sensorless Speed Controlled Drives with Induction Motors for Traction Applications, Communications - Scientific Letters of the University of Zilina, No. 2-3, 2001, ISSN 1335-4205. 